\title{
Utilização de xenoenxerto para reparação tecidual no tratamento das queimaduras: revisão integrativa de literatura
}

\author{
Use of xenograft for tissue repair in the treatment of burns: integrative literature review \\ Uso de xenograft para la reparación de tejidos en el tratamiento de quemaduras: revisión \\ integradora de la literatura
}

Recebido: 22/07/2021 | Revisado: 29/07/2021 | Aceito: 03/08/2021 | Publicado: 08/08/2021

Eduardo Brito da Silva

ORCID: https://orcid.org/0000-0002-8571-7806

Centro Universitário de Ciências e Tecnologia do Maranhão, Brasil

E-mail: eduzinhobds@gmail.com

Kaio Germano Sousa da Silva

ORCID: https://orcid.org/0000-0003-4236-6230

Faculdade do Vale Elvira Dayrell, Brasil

E-mail: kaiogsds@hotmail.com

Luana Pereira Ibiapina Coêlho

ORCID: https://orcid.org/0000-0002-2054-959X

Universidade Estadual do Maranhão, Brasil

E-mail: luana_ibiapina@ hotmail.com

Wenderson Costa da Silva

ORCID: https://orcid.org/0000-0001-6031-9775

Universidade Estadual do Maranhão, Brasil

E-mail: wendersoncosta09@ hotmail.com

Leiliane Barbosa de Aguiar

ORCID: https://orcid.org/0000-0001-7134-049X

Faculdade Evangélica do Meio Norte, Brasil

E-mail: leilianeaguiarcxs@gmail.com

Felipe Azevedo da Silva

ORCID: https://orcid.org/0000-0001-7160-7043 Centro Universitário de Ciências e Tecnologia do Maranhão, Brasil

E-mail: felipeazevedocx@hotmail.com

Amanda Kauany Pereira da Silva

ORCID: https://orcid.org/0000-0003-3317-1570

Faculdade Tecnológica e Educação Superior Profissional, Brasil

E-mail: kauanyamanda003@gmail.com

Victória Ribeiro de Sousa Marques

ORCID: https://orcid.org/0000-0002-6512-1212

Centro Universitário de Ciências e Tecnologia do Maranhão, Brasil

E-mail: marquesvick24@gmail.com

Lara Beatriz de Sousa Coelho

ORCID: https://orcid.org/0000-0002-8640-7172

Centro Universitário de Ciências e Tecnologia do Maranhão, Brasil

E-mail: larabiacoelho@gmail.com

Rafael Fernandes de Melo

ORCID: https://orcid.org/0000-0002-9691-4362

Centro Universitário de Ciências e Tecnologia do Maranhão, Brasil

E-mail: rafaellffernandes1001@gmail.com
Danielle Carvalho Rocha

ORCID: https://orcid.org/0000-0002-4022-037X

Universidade Estadual do Maranhão, Brasil E-mail: daniellerocha.slz@gmail.com

Rondinelle dos Santos Chaves

ORCID: https://orcid.org/0000-0003-4941-8005

Instituo Sírio-Libanês de Ensino e Pesquisa, Brasil E-mail: rondinelledsch@hotmail.com

Eudilene da Silva Mesquita

ORCID: https://orcid.org/0000-0001-9894-0903

Centro Universitário de Ciências e Tecnologia do Maranhão, Brasil

E-mail: eu.mesquitta@gmail.com

Bruna Rafaelle Pereira Ibiapina Coêlho

ORCID: https://orcid.org/0000-0002-3122-4803

Escola de Saúde Pública do Ceará, Brasil E-mail: bruna.ibiapina@hotmail.com 


\author{
George do Carmo Leão \\ ORCID: https://orcid.org/0000-0001-9106-1500 \\ Centro Universitário de Ciências e Tecnologia do Maranhão, Brasil \\ E-mail: georgeleao13@gmail.com \\ Jesica Cristina Lira dos Santos \\ ORCID: https://orcid.org/0000-0003-1902-585X \\ Universidade Estadual do Maranhão, Brasil \\ E-mail: jecristinalira@gmail.com \\ Isadora Sayonara Ferreira Coelho \\ ORCID: https://orcid.org/0000-0002-3300-6244 \\ Centro Universitário de Ciências e Tecnologia do Maranhão, Brasil \\ E-mail: isaaebella3006@gmail.com \\ Milka Esthefanni dos Santos Passos Oliveira \\ ORCID: https://orcid.org/0000-0002-1743-9496 \\ Centro Universitário de Ciências e Tecnologia do Maranhão, Brasil \\ E-mail: Milka.esthefanne56@gmail.com \\ Geovanna Clara Cunha Lima Ferreira \\ ORCID: https://orcid.org/0000-0003-1073-0069 \\ Centro Universitário de Ciências e Tecnologia do Maranhão, Brasil \\ E-mail: geovannaclara@hotmail.com \\ Thalita Cristina Oliveira Santos \\ ORCID: https://orcid.org/0000-0002-4284-7328 \\ Centro Universitário de Ciências e Tecnologia do Maranhão, Brasil \\ E-mail: thalitacristina181@gmail.com \\ Ianca Sabrina Silva Nascimento \\ ORCID: https://orcid.org/0000-0002-2825-5107 \\ Centro Universitário de Ciências e Tecnologia do Maranhão, Brasil \\ E-mail: silvaiannca@gmail.com \\ Sara Tereza Lisboa dos Santos \\ ORCID: https://orcid.org/0000-0001-8097-3758 \\ Centro Universitário de Ciências e Tecnologia do Maranhão, Brasil \\ E-mail: saratereza7@gmail.com \\ Jeslaine Da Silva Alves Viana \\ ORCID: https://orcid.org/0000-0003-2430-3746 \\ Centro Goiano De Ensino, Pesquisa e Pós, Brasil \\ E-mail: Jeslaine.enfermeira@ gmail.com \\ Wanderson de Almeida Silva \\ ORCID: https://orcid.org/0000-0001-5407-0096 \\ Centro Universitário de Ciências e Tecnologia do Maranhão, Brasil \\ E-mail:wa369902@gmail.com \\ Laianny Luize Lima e Silva \\ ORCID: https://orcid.org/0000-0003-2553-6656 \\ Universidade Federal do Piauí, Brasil \\ E-mail: laiannyluizelimaesilva@gmail.com
}

\title{
Resumo
}

Tecidos biológicos de origem animal, como pele de porco, pele de rã, pericárdio bovino e submucosa intestinal de porco têm sido utilizados em curativos biooclusivos (xenotransplantes) para queimaduras. O presente estudo objetivou analisar a utilização da terapia com xenoenxerto no tratamento de queimaduras. Trata-se de uma revisão integrativa da literatura, na qual se formulou a seguinte questão clínica: "Quais as evidências científicas acerca da utilização da terapia com xenoenxerto na reparação tecidual de pacientes vítimas de queimaduras?”. Foram consultadas bases de dados PubMed, Bireme e CINAHL. Utilizaram-se estudos disponíveis em sua totalidade, publicados nos anos de 2016 até 2021, nos idiomas Português, Espanhol e Inglês. Oito estudos foram incluídos nesta revisão. Os estudos abordaram as características da utilização de xenoenxerto como curativo biológico na terapia em pacientes queimados quanto sexo, tipo de queimadura, grau de queimadura, porcentagem da área acometida, tipo de curativo biológico, indicação, tempo de intervenção e evolução dos casos. Os resultados concluem que o uso de xenotransplantes tem se mostrado eficaz na diminuição de algias, diminuição da internação hospitalar, reepitelização mais rápida, menor trocas de curativos, menor custo benefício, diminuição de infecções. O estudo permitiu uma avaliação do tratamento de queimaduras por meio da terapia com curativo heterólogo, concluindo que ele é eficaz, além disso, concluiu-se que o curativo com pele de tilápia do Nilo teve resultados estatisticamente mais significativos, quando comparado a todas intervenções, incluindo com curativo biológico porcino.

Palavras-chave: Queimaduras; Xenoenxertos; Cicatrização.

\begin{abstract}
Biological tissues of animal origin, such as pig skin, frog skin, bovine pericardium and pig intestinal submucosa have been used in bioocclusive dressings (xenotransplantation) for burns. The present study aimed to analyze the use of xenograft therapy in the treatment of burns. This is an integrative literature review, in which the following clinical
\end{abstract}


question was formulated: "What is the scientific evidence on the use of xenograft therapy in tissue repair in burn victims?". PubMed, Bireme and CINAHL databases were consulted. Studies available in their entirety, published from 2016 to 2021, in Portuguese, Spanish and English, were used. Eight studies were included in this review. The studies addressed the characteristics of the use of xenograft as a biological dressing in the therapy of burn patients, such as gender, type of burn, degree of burn, percentage of affected area, type of biological dressing, indication, intervention time and evolution of cases. The results conclude that the use of xenotransplantation has been shown to be effective in reducing pain, reducing hospital stays, faster re-epithelialization, less dressing changes, lower costeffectiveness, and fewer infections. The study allowed an evaluation of the treatment of burns through heterologous dressing therapy, concluding that it is effective, in addition, it was concluded that the Nile tilapia skin dressing had statistically more significant results when compared to all interventions, including with porcine biological dressing.

Keywords: Burns; Heterografts; Wound healing.

\section{Resumen}

Los tejidos biológicos de origen animal, como piel de cerdo, piel de rana, pericardio bovino y submucosa intestinal de cerdo, se han utilizado en apósitos biooclusivos (xenotrasplantes) para quemaduras. El presente estudio tuvo como objetivo analizar el uso de la terapia con xenoinjertos en el tratamiento de quemaduras. Se trata de una revisión integradora de la literatura, en la que se formuló la siguiente pregunta clínica: “¿Cuál es la evidencia científica sobre el uso de la terapia con xenoinjerto en la reparación de tejidos en víctimas de quemaduras?”. Se consultaron las bases de datos PubMed, Bireme y CINAHL. Se utilizaron los estudios disponibles en su totalidad, publicados de 2016 a 2021, en portugués, español e inglés. En esta revisión se incluyeron ocho estudios. Los estudios abordaron las características del uso de xenoinjerto como apósito biológico en la terapia de pacientes quemados, tales como sexo, tipo de quemadura, grado de quemadura, porcentaje de área afectada, tipo de apósito biológico, indicación, tiempo de intervención y evolución de casos. Los resultados concluyen que el uso de xenotrasplantes ha demostrado ser eficaz para reducir el dolor, reducir las estancias hospitalarias, una reepitelización más rápida, menos cambios de apósitos, menor rentabilidad y menos infecciones. El estudio permitió evaluar el tratamiento de las quemaduras mediante apósito heterólogo, concluyendo que es efectivo, además, se concluyó que el apósito de piel de tilapia del Nilo tuvo resultados estadísticamente más significativos en comparación con todas las intervenciones, incluso con apósito biológico porcino.

Palabras clave: Quemaduras; Xenoinjertos; Cicatrización de heridas.

\section{Introdução}

A queimadura é uma lesão cutânea causada parcial ou totalmente por agentes externos, como calor, eletricidade, ação química ou radioativa, que atinge e pode destruir certa faixa da superfície corporal (Dalla-Corte, Fleury, Huang, Adorno, \& Modelli, 2019). Trata-se de uma lesão extremamente agressiva que pode atingir camadas profundas, como tecido muscular, tendões e ossos, causando perda de membros, função, movimento ou morte (Belém, 2016).

Independentemente do seu grau, o trauma térmico é um comportamento agressivo que pode causar danos físicos e psicológicos ao paciente. Para pacientes com queimaduras que precisam ser hospitalizados, a situação é ainda mais complicada, porque será afetado por vários estresses físicos, como acidose, perda de fluidos, alterações no equilíbrio endócrino, possibilidade de infecção, dor e estresse psicológico, causados pela separação familiar, ausência ao trabalho, mudanças físicas, despersonalização, dependência de cuidados, perda de autonomia e tensão constante (Carlucci, Rossi, Ficher, Ferreira, \& Carvalho, 2007).

O maior risco para as mulheres está associado ao desempenho de atividades, como cozimento em fogo aberto ou em fogões, em situação não seguras. Chamas abertas usadas para aquecimento e iluminação também representam riscos, bem como a violência autodirigida ou interpessoal. Em todos os países, o risco de queimaduras está relacionado ao padrão socioeconômico. Pesquisa mostra que entre as populações de renda baixa a média os riscos de queimaduras são maiores do que nas populações com alta renda (Organização Mundial da Saúde, 2018).

Estudo recente demonstrou que a pele de tilápia do Nilo (Oreochromis niloticus) é utilizada na medicina regenerativa como biomaterial, com boa adesão na superfície de feridas de ratos. Quando comparada com a pele humana em análises histológicas, histoquímicas e de tração, o teste apresentou resultados de organização satisfatórios. A pele da tilápia apresenta boa resistência à tração e compressão, podendo ser utilizada como curativo biológico para queimaduras (De Miranda \& Brandt, 
2019). Tecidos biológicos oriundos de origem animal, como por exemplo pele de porco, de rã, submucosa intestinal de porco e pericárdio bovino, vêm sendo usados em curativos do tipo biooclusivos (xenotransplantes) para queimaduras (Alves et al., 2015).

O tempo necessário para a cicatrização da ferida é um dos principais determinantes do desenvolvimento de complicações, sendo a infecção a principal causa de morte em pacientes queimados. Muitos estudos têm sido realizados para identificar curativos que podem reduzir a contaminação da ferida, possibilitando o processo de cicatrização e proporcionando melhores resultados estéticos, assim, os materiais biológicos têm sido buscados como preferência econômica para o tratamento de lesões térmicas (Lima et al., 2020a).

Este estudo apresenta como questão norteadora: "Quais as evidências científicas acerca da utilização da terapia com xenoenxerto na reparação tecidual de pacientes vítimas de queimaduras". Para tal, elaborou-se como objetivo geral: descrever a utilização da terapia com xenoenxerto no tratamento de queimaduras; e especificamente objetivou-se conhecer o tratamento de queimaduras com tecidos transplantados de animais de diferentes espécies; identificar, entre os tipos de transplantes heterólogos, o mais indicado no tratamento de queimaduras; e descrever a indicação do tratamento com xenoenxerto de acordo com o tipo de queimadura. A relevância deste trabalho justifica-se pelo fato de as queimaduras representarem um problema sério de saúde pública, portanto os resultados deste estudo poderão contribuir, a partir de dados atualizados, para subsidiar a assistência de Enfermagem na intervenção mais eficaz em pacientes queimados.

O enfermeiro assiste constantemente o paciente queimado, portanto, sua participação na educação em saúde tem papel fundamental não só no hospital, mas também na reintegração do paciente para que ele não precise mais da enfermagem na retomada de seu dia a dia (Pinho et al., 2017). Por fim, é notável a seriedade do assunto, na medida em que o possível produto da pesquisa poderá contribuir não só para a comunidade científica, como também para a comunidade leitora, como informação e orientação acerca do assunto, tendo em vista, que há espaço para novos estudos e para a busca de novas alternativas terapêuticas das queimaduras no país.

\section{Metodologia}

O presente estudo tratou-se de uma pesquisa bibliográfica do tipo revisão integrativa da literatura, procedimento escolhido por possibilitar a síntese e análise do conhecimento científico já produzido. Essa revisão utilizou a metodologia proposta no estudo de Oliveira et al. (2016).

De acordo com Ercole, Melo e Alcoforado (2014), a revisão integrativa da literatura é um método que visa usar diferentes métodos para sintetizar os resultados da pesquisa de forma sistemática, ordenada e abrangente. É denominado "integrativa", porque fornece informações mais amplas sobre um assunto, constitui um sistema de conhecimento e pode ser usado para definição de conceitos, revisão teórica ou análise de metodologia de pesquisa. Esse método fornece uma combinação de dados da literatura teórica e empírica para que você tenha um melhor entendimento do tema de interesse.

O tema "UTILIZAÇÃO DE XENOENXERTO PARA REPARAÇÃO TECIDUAL NO TRATAMENTO DAS QUEIMADURAS: revisão integrativa de literatura”, determinou a construção da estratégia PICO, que representa um acrônimo para Paciente (P), Intervenção (I), Comparação (C) e Desfechos (O-outcomes), que foi utilizada para a geração da questão norteadora desta revisão integrativa da literatura: "Quais as evidências científicas acerca da utilização da terapia com xenoenxerto na reparação tecidual de pacientes vítimas de queimaduras?".

Para a localização dos estudos relevantes, que respondessem à pergunta de pesquisa, utilizaram-se de descritores indexados e não indexados (palavras-chave) nos idiomas português, inglês e espanhol. Os descritores foram obtidos a partir do Medical Subject Headings (MESH), dos Descritores em Ciências da Saúde (DeCS) e dos títulos CINAHL, como mostra o Quadro 1. Consultaram-se por meio de descritores e palavras-chave as bases de dados PubMed da National Library of 
Medicine; BVS (Biblioteca Virtual da Saúde), coordenada pela BIREME e composta de bases de dados bibliográficas produzidas pela Rede BVS, como LILACS, além da base de dados Medline e outros tipos de fontes de informação; e CINAHL (Cumulative Index to Nursing and Allied Health Literature).

Quadro 1. Elementos da estratégia PICO, descritores e palavras-chave utilizados. Caxias, MA, Brasil, 2021.

\begin{tabular}{|c|c|c|c|c|c|}
\hline & Elementos & Mesh & Decs & Títulos Cinahl & Palavras-chave \\
\hline $\mathbf{P}$ & Queimaduras & "Burns" & $\begin{array}{l}\text { "Queimaduras" } \\
\text { "Burns" } \\
\text { "Quemaduras" }\end{array}$ & "Burns" & "Queimaduras" \\
\hline $\mathbf{I}$ & Xenoenxerto & "Heterografts" & $\begin{array}{l}\text { "Xenoenxertos" } \\
\text { "Heterografts" } \\
\text { "Xenoinjertos" }\end{array}$ & "Xenografts" & "Xenoenxerto" \\
\hline $\mathbf{C}$ & - & - & - & - & - \\
\hline $\mathbf{O}$ & $\begin{array}{c}\text { Reparação } \\
\text { tecidual }\end{array}$ & "Treatment Outcome" & $\begin{array}{c}\text { "Cicatrização" } \\
\text { "Wound Healing" } \\
\text { "Cicatrización de } \\
\text { Heridas" }\end{array}$ & "Wound Healing" & "Cicatrização" \\
\hline
\end{tabular}

Fonte: Descritores, Títulos e Palavras-chaves (2021).

O elemento $\mathrm{C}$ da estratégia PICO não será abordado nesta pesquisa pois esta não tem por objetivo comparar intervenções. Os termos utilizados durante a pesquisa foram classificados e combinados nos bancos de dados, resultando em estratégias específicas de cada base, como se mostra no Quadro 2, a seguir.

Quadro 2. Estratégias de busca utilizadas nas bases de dados BIREME, PUBMED e CINAHL. Caxias, MA, Brasil, 2021.

\begin{tabular}{|c|c|c|c|c|}
\hline BASE DE DADOS & ESTRATÉGIA DE BUSCA & 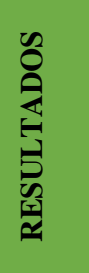 & 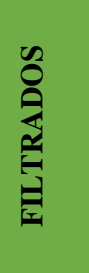 & 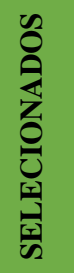 \\
\hline $\begin{array}{c}\text { BIREME } \\
\text { (descritores Decs) }\end{array}$ & $\begin{array}{l}\text { Queimaduras AND Xenoenxertos AND } \\
\text { Cicatrização }\end{array}$ & 163 & 29 & 2 \\
\hline $\begin{array}{c}\text { PubMed } \\
\text { (descriptors MeSH) }\end{array}$ & Burns AND Xenografts AND Treatment Outcome & 32 & 9 & 3 \\
\hline $\begin{array}{c}\text { CINAHL } \\
\text { (CINAHL Headings) }\end{array}$ & Burns AND Xenografts AND Wound Healing & 24 & 12 & 3 \\
\hline
\end{tabular}

Fonte: Base de dados (2021).

\section{Critérios de inclusão e exclusão}

Como critérios de inclusão foram utilizados estudos disponíveis, publicados nos últimos cinco anos, de 2016 até 2021, nos idiomas Português, Espanhol e Inglês. Foram excluídos da busca inicial capítulos de livros, resumos, textos incompletos, teses, dissertações, monografias, relatos técnicos e outras formas de publicação que não artigos científicos completos.

\section{Identificação dos estudos pré-selecionados e selecionados}

A análise para seleção dos estudos foi realizada em duas fases, a saber: na primeira, os estudos foram préselecionados segundo os critérios de inclusão e exclusão e de acordo com a estratégia de funcionamento e busca de cada base de dados. 
Encontraram-se cento e sessenta e três (163) estudos como busca geral na BVS. A partir da aplicação dos critérios de inclusão, pesquisa realizada com humanos nos últimos cinco anos, obtiveram-se vinte e nove (29) estudos, títulos e resumos foram analisados e apenas dois (2) estudos foram condizentes com a questão desta pesquisa.

Na base PUBMED, como busca total foram encontrados trinta e dois (32) estudos, que, depois de filtrados por texto completo dos últimos cinco anos, de pesquisa com humanos, chegou-se a nove (9) estudos, cujos títulos e resumos foram analisados e chegou-se ao resultado final de três (3) estudos.

$\mathrm{Na}$ CINAHL, foram obtidos vinte e quatro (24) estudos a partir da busca geral. Depois de aplicados os critérios texto completo de pesquisa realizada nos últimos cinco anos com humanos, chegou-se a doze (12) estudos, dos quais só três (3) foram condizentes com a questão desta pesquisa após a análise dos títulos e resumos.

$\mathrm{Na}$ segunda fase os estudos foram analisados quanto ao potencial de participação no estudo, avaliando o atendimento à questão de pesquisa, bem como o tipo de investigação, objetivos, amostra, método, desfechos, resultados e conclusão, resultando em oito (8) artigos que atenderam à questão norteadora e foram adicionados ao estudo.

Figura 1. Fluxograma do processo de seleção dos estudos para a revisão integrativa. Caxias, MA, Brasil, 2021.

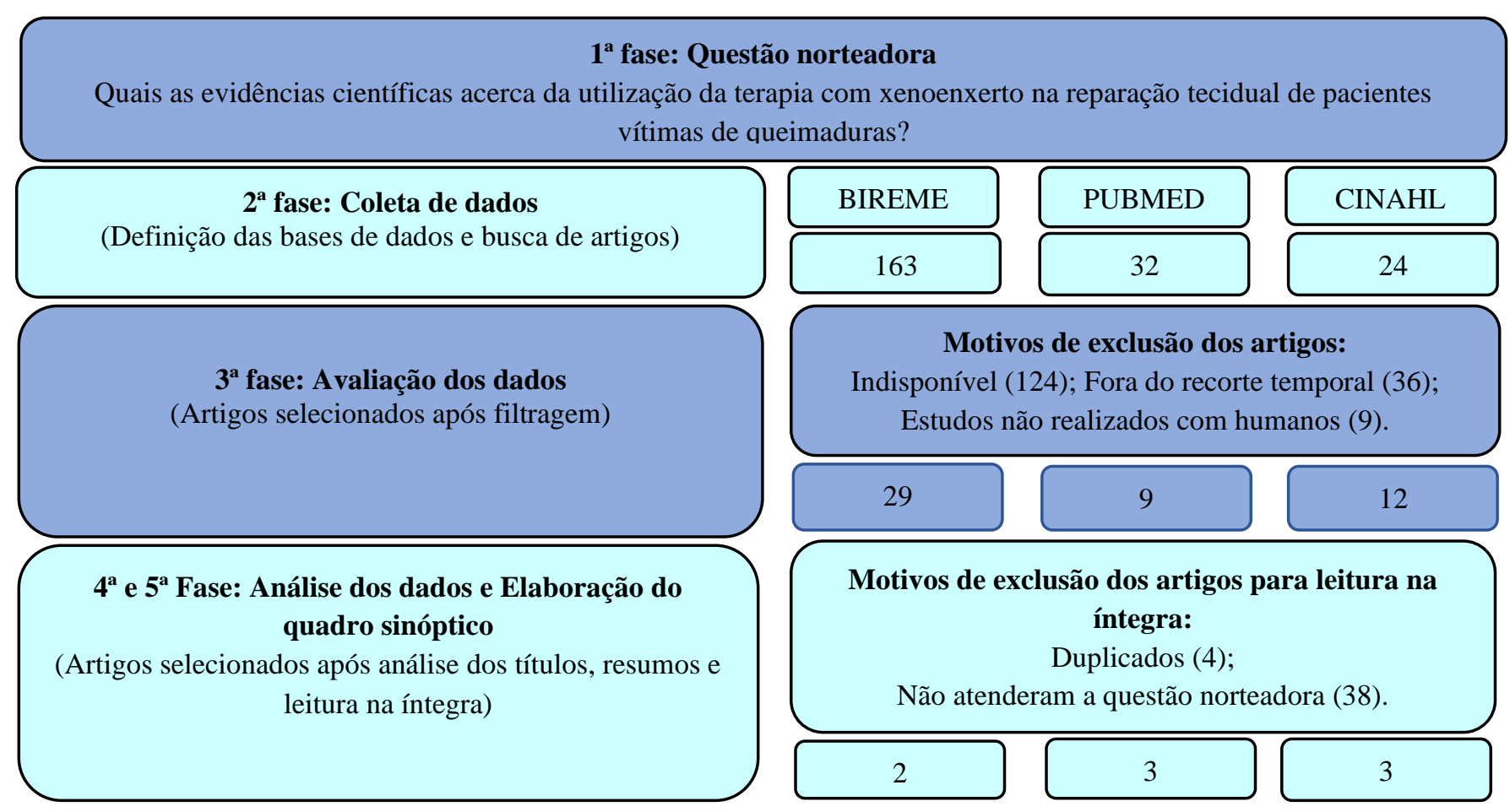

Fonte: Base de dados (2021).

\section{Análise e interpretação dos resultados}

Nesta etapa foram analisadas as informações coletadas nos artigos científicos e foram criadas categorias analíticas, o que facilitou a ordenação e a sumarização de cada estudo. Essa categorização foi realizada de forma descritiva, indicando os dados mais relevantes para o estudo. A pesquisa levou em consideração os aspectos éticos quanto às citações dos estudos, respeitando a autoria das ideias, os conceitos e as definições presentes nos artigos incluídos na revisão.

Optou-se pela análise em forma estatística e de forma de texto, utilizando cálculos matemáticos e inferências, que serão apresentados em quadros e tabelas para facilitar a visualização e compreensão. As evidências científicas foram classificadas segundo os níveis e graus de recomendação propostos por Bork (2011), como mostra a Figura 2, a seguir: 
Figura 2. Níveis de evidência e graus de recomendação.

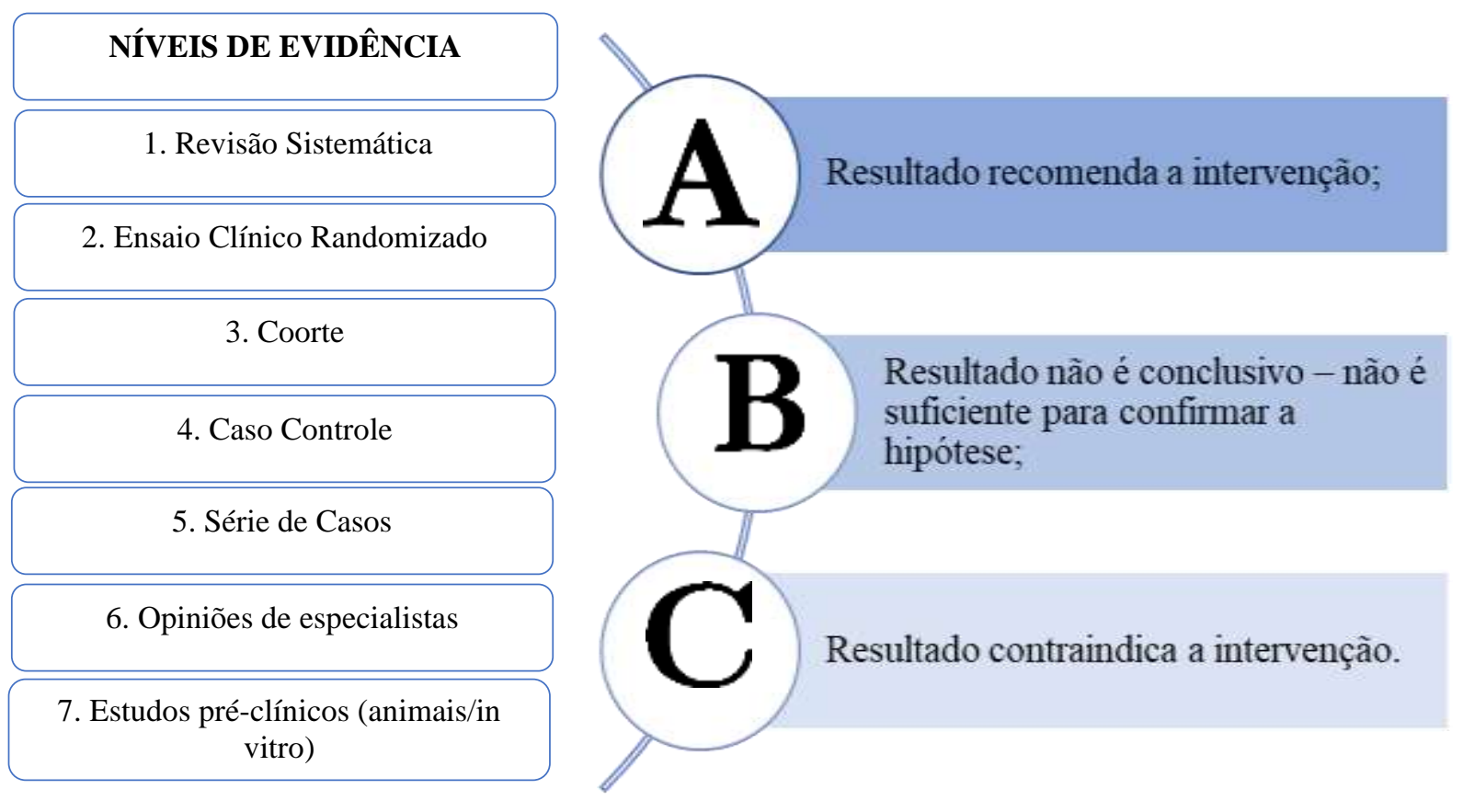

Fonte: Adaptado de Bork (2011).

\section{Resultados}

Essa fase é organizada em duas partes, a saber: a primeira está relacionada à caracterização dos estudos; a segunda relaciona-se ao cumprimento do objetivo do estudo, que consiste em conhecer o tratamento de queimaduras por meio de curativos biológicos.

\section{Caracterização dos estudos}

Foram incluídos oito estudos nesta revisão, a maioria dos quais concentrados nas bases de dados Pubmed e Bireme (37,5\%, cada). Em relação aos resultados, a abordagem quantitativa dos dados foi a mais prevalente $(n=7 / 87,5 \%)$ entre os artigos analisados. Com relação ao ano e idioma, a maioria dos estudos concentrou-se no ano de 2019 (50,0\%); e houve predomínio do idioma inglês $(75,0 \%)$. O Brasil foi o país com mais estudos incluídos, seguido dos Estados Unidos (50,0\% e $25,0 \%$, respectivamente).

O periódico que mais se destacou foi a Revista Brasileira de Cirurgia Plástica, com 25,0\%. Os outros periódicos tiveram o percentual de $12,5 \%$, cada. O nível de evidência científica de pesquisa foi alto, sendo composto principalmente por ensaios clínicos randomizados $(50,0 \%)$. Quanto ao grau de recomendação, o mais prevalente foi o "A" para a prática clínica, conforme demostrando na Tabela 1, a seguir. 
Tabela 1. Análise descritiva das produções científicas acerca do uso de curativos biológicos no tratamento de queimaduras. Caxias, MA, Brasil, 2021. ( $\mathrm{N}=8)$.

\begin{tabular}{|c|c|c|}
\hline Variáveis & $\mathbf{N}$ & $\%$ \\
\hline \multicolumn{3}{|l|}{ Base de dados } \\
\hline BIREME & 2 & 25,0 \\
\hline PUBMED & 3 & 37,5 \\
\hline CINAHL & 3 & 37,5 \\
\hline \multicolumn{3}{|l|}{ Abordagem do estudo } \\
\hline Quantitativo & 7 & 87,5 \\
\hline Qualitativo & 1 & 12,5 \\
\hline \multicolumn{3}{|l|}{ Áno } \\
\hline 2016 & 1 & 12,5 \\
\hline 2017 & 1 & 12,5 \\
\hline 2018 & 1 & 12,5 \\
\hline 2019 & 4 & 50,0 \\
\hline 2020 & 1 & 12,5 \\
\hline \multicolumn{3}{|l|}{ Idiomas } \\
\hline Português & 2 & 25,0 \\
\hline Inglês & 6 & 75,0 \\
\hline \multicolumn{3}{|l|}{ País } \\
\hline Brasil & 4 & 50,0 \\
\hline Estados Unidos & 2 & 25,0 \\
\hline Suécia & 1 & 12,5 \\
\hline Reino Unido & 1 & 12,5 \\
\hline \multicolumn{3}{|l|}{ Delineamento de pesquisa } \\
\hline Ensaio Clínico Randomizado & 4 & 50,0 \\
\hline Estudo de Caso & 1 & 12,5 \\
\hline Estudo de Coorte & 1 & 12,5 \\
\hline Série de Casos & 1 & 12,5 \\
\hline Estudo Transversal & 1 & 12,5 \\
\hline \multicolumn{3}{|l|}{ Classificação da evidência } \\
\hline Nível 2 & 4 & 50,0 \\
\hline Nível 3 & 1 & 12,5 \\
\hline Nível 5 & 2 & 25,0 \\
\hline Nível 6 & 1 & 12,5 \\
\hline \multicolumn{3}{|l|}{ Grau de recomendação } \\
\hline A & 6 & 75,0 \\
\hline $\mathrm{B}$ & 2 & 25,0 \\
\hline \multicolumn{3}{|l|}{ Periódicos } \\
\hline Journal of Burn Care \& Research & 1 & 12,5 \\
\hline Military Medicine & 1 & 12,5 \\
\hline American Burn Association & 1 & 12,5 \\
\hline Clinics in Plastic Surgery & 1 & 12,5 \\
\hline Journal Of Wound Care & 1 & 12,5 \\
\hline Burns & 1 & 12,5 \\
\hline Revista Brasileira de Cirurgia Plástica & 2 & 25,0 \\
\hline
\end{tabular}

Fonte: Base de dados (2021).

O Quadro 3 mostra a distribuição dos estudos segundo autores e anos de publicação (título; autor; ano; objetivo e perfil amostral). A maioria dos estudos versaram sobre o uso de curativo biológico de pele de Tilápia do Nilo e porcino como xenoenxerto para o tratamento de queimaduras de primeiro e segundo graus comparado ao tratamento convencional. $\mathrm{O}$ tratamento envolveu pacientes pediátricos (de 6 meses a 12 anos), adultos (de 18 a 50 anos) e idosos (de 60 a 80 anos). 
Research, Society and Development, v. 10, n. 10, e175101018560, 2021

(CC BY 4.0) | ISSN 2525-3409 | DOI: http://dx.doi.org/10.33448/rsd-v10i10.18560

Quadro 3. Publicações incluídas segundo o título do artigo, autor, objetivo principal e perfil amostral e delineamento de pesquisa. Caxias, MA, Brasil. 2021. (N=08)

\begin{tabular}{|c|c|c|c|c|c|}
\hline $\begin{array}{l}\mathbf{N}^{\circ} \mathrm{DE} \\
\text { ORDEM E } \\
\text { BASE }\end{array}$ & TÍTULO DO ARTIGO & $\begin{array}{l}\text { AUTOR/ } \\
\text { ANO }\end{array}$ & OBJETIVO PRINCIPAL & PERFIL AMOSTRAL & $\begin{array}{l}\text { DELINEAMENTO } \\
\text { DE } \\
\text { PESQUISA } \\
\end{array}$ \\
\hline $\begin{array}{c}\text { A1 } \\
\text { BIREME }\end{array}$ & $\begin{array}{l}\text { Xenoenxerto (pele da Tilápia- } \\
\text { do-Nilo) e hidrofibra com prata } \\
\text { no tratamento das queimaduras } \\
\text { de II grau em adultos }\end{array}$ & $\begin{array}{l}\text { De Miranda } \\
\text { e Brandt } \\
(2019)\end{array}$ & $\begin{array}{l}\text { Avaliar a eficácia da utilização da pele da Tilápia-do-Nilo } \\
\text { (Oreochromis niloticus) como curativo biológico oclusivo, } \\
\text { no manejo/tratamento de queimaduras de } 2^{\circ} \text { grau em } \\
\text { adultos. }\end{array}$ & $\begin{array}{l}30 \text { pacientes com presença de queimaduras de II } \\
\text { grau superficial e/ou profundo, acometendo até } \\
10 \% \text { de superfície corporal queimada; injúria } \\
\text { ocorrida no máximo há } 72 \text { horas; idade entre } 20 \text { a } \\
60 \text { anos; ausência de tratamento prévio para a } \\
\text { queimadura atual e de comorbidades } \\
\text { significativas. }\end{array}$ & $\begin{array}{l}\text { Ensaio Clínico } \\
\text { Randomizado }\end{array}$ \\
\hline $\begin{array}{c}\text { A2 } \\
\text { BIREME }\end{array}$ & $\begin{array}{l}\text { Tratamento de queimaduras de } \\
\text { segundo grau profundo em } \\
\text { abdômen, coxas e genitália: uso } \\
\text { da pele de tilápia como um } \\
\text { xenoenxerto }\end{array}$ & $\begin{array}{l}\text { Lima et al. } \\
(2020 b)\end{array}$ & $\begin{array}{l}\text { Relatar o caso de uma paciente com queimaduras de } \\
\text { segundo grau profundo envolvendo genitália e região } \\
\text { inguinal, entre outras áreas, em que foi feito tratamento } \\
\text { com o uso da pele de tilápia como xenoenxerto. }\end{array}$ & $\begin{array}{l}\text { Uma paciente do sexo feminino, } 18 \text { anos, sem } \\
\text { comorbidades, com queimaduras de segundo grau } \\
\text { profundo em abdômen, região inguinal, parte da } \\
\text { genitália e metade superior de ambas as coxas, } \\
\text { envolvendo } 13,5 \% \text { da área total da superfície } \\
\text { corporal. }\end{array}$ & Estudo de caso \\
\hline $\begin{array}{c}\text { A3 } \\
\text { PUBMED }\end{array}$ & $\begin{array}{l}\text { Even Better Than the Real } \\
\text { Thing? Xenografting in Pediatric } \\
\text { Patients with Scald Injury }\end{array}$ & $\begin{array}{l}\text { Diegidio et } \\
\text { al. (2017) }\end{array}$ & $\begin{array}{l}\text { Relatar uma experiência de } 10 \text { anos com queimaduras por } \\
\text { escaldadura pediátrica, comparando três técnicas diferentes } \\
\text { de fechamento de feridas: tratamento não operatório, } \\
\text { xenoenxerto e autoenxerto. }\end{array}$ & $\begin{array}{l}1867 \text { indivíduos menores de } 18 \text { anos com lesão } \\
\text { por escaldadura, estratificados em } 3 \text { coortes com } \\
\text { base no método de fechamento da ferida: (1) } \\
\text { tratamento não operatório com cuidados locais } \\
\text { apenas para feridas; (2) desbridamento operatório } \\
\text { e xenoenxerto da lesão por escalda; e (3) preparo } \\
\text { excisional e autoenxerto da lesão por escalda. }\end{array}$ & Estudo de Coorte \\
\hline $\begin{array}{c}\text { A4 } \\
\text { PUBMED }\end{array}$ & $\begin{array}{l}\text { Porcine xenograft treatment of } \\
\text { superficial partial-thickness } \\
\text { burns in paediatric patients }\end{array}$ & $\begin{array}{l}\text { Burkey, } \\
\text { Davis e Glat } \\
\text { (2016) }\end{array}$ & $\begin{array}{l}\text { Descrever uma experiência de três anos com o uso de } \\
\text { xenoenxerto porcino em queimaduras pediátricas. }\end{array}$ & $\begin{array}{l}\text { Pacientes pediátricos ( } 98 \text { meninas, } 66 \text { meninos) } \\
\text { com lesão por queimaduras. Foram incluídos } \\
\text { todos os pacientes que apresentavam mistura de } \\
\text { queimaduras parciais superficiais e queimaduras } \\
\text { profundas ou indeterminadas. Os pacientes } \\
\text { entubados foram excluídos. }\end{array}$ & Estudo transversal \\
\hline $\begin{array}{c}\text { A5 } \\
\text { PUBMED }\end{array}$ & $\begin{array}{l}\text { Superiority of silver-foam over } \\
\text { porcine xenograft dressings for } \\
\text { treatment of scalds in children: } \\
\text { A prospective randomised } \\
\text { controlled trial }\end{array}$ & $\begin{array}{l}\text { Karlsson et } \\
\text { al. (2019) }\end{array}$ & $\begin{array}{l}\text { Comparar duas intervenções diferentes para o tratamento } \\
\text { de crianças com escaldaduras de espessura parcial, } \\
\text { xenoenxerto porcino e curativo de espuma de prata. }\end{array}$ & $\begin{array}{l}58 \text { pacientes pediátricos, com idade entre } 6 \text { meses } \\
\text { e } 6 \text { anos, com lesão por escaldadura de espessura } \\
\text { parcial, internados entre maio de } 2015 \text { e maio de } \\
2018 \text {. }\end{array}$ & $\begin{array}{l}\text { Ensaio Clínico } \\
\text { Randomizado }\end{array}$ \\
\hline $\begin{array}{c}\text { A6 } \\
\text { CINAHL }\end{array}$ & $\begin{array}{l}\text { Innovative Burn Treatment } \\
\text { Using Tilapia Skin as a } \\
\text { Xenograft: A Phase } \\
\text { Randomized Controlled Trial }\end{array}$ & $\begin{array}{l}\text { Lima Júnior } \\
\text { et al. } \\
\text { (2020a) }\end{array}$ & $\begin{array}{l}\text { Avaliar a eficácia da tilápia do Nilo (Oreochromis } \\
\text { niloticus) pele como curativo de xenoenxerto oclusivo para } \\
\text { o tratamento de queimaduras em humanos. }\end{array}$ & $\begin{array}{l}62 \text { pacientes de ambos os sexos, com idade de } 18 \\
\text { a } 50 \text { anos e presença de feridas dermatológicas } \\
\text { causadas por queimaduras superficiais de } \\
\text { espessura parcial. }\end{array}$ & $\begin{array}{l}\text { Ensaio Clínico } \\
\text { Randomizado }\end{array}$ \\
\hline A7 & $\begin{array}{l}\text { Acellular Fish Skin Grafts for } \\
\text { Management of Split Thickness }\end{array}$ & $\begin{array}{l}\text { Alam e } \\
\text { Jeffery }\end{array}$ & $\begin{array}{l}\text { Usar a pele de peixe acelular em vítimas de queimaduras no } \\
\text { Burn Center do Queen Elizabeth Hospital Birmingham, }\end{array}$ & $\begin{array}{l}\text { Dez pacientes, seis homens e quatro mulheres, } \\
\text { foram incluídos no estudo do local doador. A }\end{array}$ & Série de Casos \\
\hline
\end{tabular}


Research, Society and Development, v. 10, n. 10, e175101018560, 2021

(CC BY 4.0) | ISSN 2525-3409 | DOI: http://dx.doi.org/10.33448/rsd-v10i10.18560

\begin{tabular}{|c|c|c|c|c|c|}
\hline CINAHL & $\begin{array}{l}\text { Donor Sites and Partial } \\
\text { Thickness Burns: A Case Series }\end{array}$ & (2019) & $\begin{array}{l}\text { como um piloto para informar futuros estudos } \\
\text { randomizados controlados. }\end{array}$ & $\begin{array}{l}\text { idade média dos pacientes era de } 45 \text { (variação de } \\
19 \text { a 80). }\end{array}$ & \\
\hline $\begin{array}{c}\text { A8 } \\
\text { CINAHL }\end{array}$ & $\begin{array}{l}\text { Pediatric Burn Treatment Using } \\
\text { Tilapia Skin as a Xenograft for } \\
\text { Superficial-Partial Thickness } \\
\text { Wounds: a Pilot Study }\end{array}$ & $\begin{array}{l}\text { Lima et al. } \\
(2020 \mathrm{c})\end{array}$ & $\begin{array}{l}\text { Avaliar a eficácia da pele de tilápia do Nilo como um } \\
\text { xenoenxerto para o tratamento de queimaduras de } \\
\text { espessura parcial em crianças. }\end{array}$ & $\begin{array}{l}30 \text { crianças com idades entre } 2 \text { e } 12 \text { anos, com } \\
\text { queimaduras superficiais de espessura parcial, } \\
\text { admitidas há menos de } 72 \text { horas após a lesão } \\
\text { térmica. }\end{array}$ & $\begin{array}{l}\text { Ensaio Clínico } \\
\text { Randomizado }\end{array}$ \\
\hline
\end{tabular}

Fonte: Artigos analisados (2021). 


\section{Caracterização dos estudos analisados}

A caracterização clínica e demográfica dos pacientes nos estudos analisados, podem ser observadas no quadro 4, a seguir. A idade dos pacientes variou entre 6 meses a 80 anos, com dados expressivos em pacientes pediátricos e adultos (De Miranda \& Brandt, 2019; Lima et al., 2020b; Diegidio et al., 2017; Burkey, Davis, \& Glat, 2016; Karlsson et al., 2019; Lima et al., 2020a; Alam \& Jeffery, 2019; Lima et al., 2020c), dos quais foram acometidos, principalmente, indivíduos do sexo feminino (De Miranda \& Brandt, 2019; Lima et al., 2020b; Burkey et al., 2016; Karlsson et al., 2019). Com relação ao tipo de queimadura, todos os pacientes apresentaram lesão térmica (De Miranda \& Brandt, 2019; Lima et al., 2020b; Diegidio et al., 2017; Burkey et al., 2016; Karlsson et al., 2019; Lima et al., 2020a; Alam \& Jeffery, 2019; Lima et al., 2020c). As queimaduras mais comuns foram aquelas por escalduras em ambiente doméstico (Lima et al., 2020b; Diegidio et al., 2017; Burkey et al., 2016; Karlsson et al., 2019; Lima et al., 2020c) e grau II profundo e superficial de acometimento (De Miranda \& Brandt, 2019; Lima et al., 2020b; Diegidio et al., 2017; Burkey et al., 2016; Karlsson et al., 2019; Lima et al., 2020a; Alam \& Jeffery, 2019; Lima et al., 2020c). O percentual de acometimento total da superfície corporal variou entre 0,5\% a $60 \%$, com prevalência entre 10\% a 20\% (De Miranda \& Brandt, 2019; Lima et al., 2020b; Diegidio et al., 2017; Burkey et al., 2016;

Karlsson et al., 2019; Lima et al., 2020a; Lima et al., 2020c), respectivamente.

Quadro 4. Caracterização da amostra dos estudos quanto às variáveis sociodemográficas e clínicas. Caxias, MA, Brasil, 2021.

\begin{tabular}{|c|c|c|c|c|c|c|c|}
\hline $\begin{array}{c}\text { Autor e } \\
\text { ano } \\
\end{array}$ & Idade & $\operatorname{Sexo}(\mathbf{M})$ & $\operatorname{Sexo}(\mathbf{F})$ & $\begin{array}{c}\text { Tipo de } \\
\text { queimadura }\end{array}$ & Grau queimadura & $\begin{array}{l}\text { \% da área } \\
\text { acometida }\end{array}$ & Total \\
\hline $\begin{array}{c}\text { De } \\
\text { Miranda } \\
\text { e Brandt } \\
(2019) \\
\end{array}$ & $\begin{array}{l}20-60 \\
\text { anos }\end{array}$ & $\begin{array}{c}\text { Não } \\
\text { reportado }\end{array}$ & $\begin{array}{c}\text { Não } \\
\text { reportado }\end{array}$ & $\begin{array}{l}\text { Lesão térmica } \\
\text { (líquidos super } \\
\text { aquecidos) }\end{array}$ & $\begin{array}{l}\text { Queimaduras de II } \\
\text { grau (Superficial e/ou } \\
\text { profundo) }\end{array}$ & $\begin{array}{l}\text { Acometendo até } \\
10 \% \text { de superfície } \\
\text { corporal } \\
\text { queimada }\end{array}$ & 30 pacientes \\
\hline $\begin{array}{l}\text { Lima et } \\
\text { al. } \\
(2020 b)\end{array}$ & $\begin{array}{l}18-50 \\
\text { anos }\end{array}$ & $\begin{array}{l}\text { Não se } \\
\text { aplica }\end{array}$ & 1 & $\begin{array}{l}\text { Lesão térmica } \\
\text { (escalduras) }\end{array}$ & $\begin{array}{l}\text { Queimaduras de II } \\
\text { grau profundo e } \\
\text { superficial }\end{array}$ & $\begin{array}{l}\text { Acometendo até } \\
13,5 \% \text { da área } \\
\text { total da superfície } \\
\text { corporal }\end{array}$ & 1 Ipacientes \\
\hline $\begin{array}{l}\text { Diegidio } \\
\text { et al. } \\
(2017)\end{array}$ & $\begin{array}{c}3-6 \\
\text { anos }\end{array}$ & $\begin{array}{c}\text { Não } \\
\text { reportado }\end{array}$ & $\begin{array}{c}\text { Não } \\
\text { reportado }\end{array}$ & $\begin{array}{l}\text { Lesão térmica } \\
\text { (escalduras) }\end{array}$ & $\begin{array}{l}\text { Queimaduras de II } \\
\text { grau profundo e } \\
\text { superficial }\end{array}$ & $\begin{array}{l}\text { Acometendo até } \\
8,08 \% \text { da área } \\
\text { total da superfície } \\
\text { corporal }\end{array}$ & $\begin{array}{c}1867 \\
\text { pacientes }\end{array}$ \\
\hline $\begin{array}{l}\text { Burkey } \\
\text { et al. } \\
(2016)\end{array}$ & $\begin{array}{l}\text { Não } \\
\text { reporta } \\
\text { do }\end{array}$ & 66 & 98 & $\begin{array}{l}\text { Lesões } \\
\text { térmicas } \\
\text { (escalduras e } \\
\text { chamas) }\end{array}$ & $\begin{array}{l}\text { Queimaduras de II } \\
\text { grau, superficial de } \\
\text { espessura parcial }\end{array}$ & $\begin{array}{l}\text { Variou de } 0,5 \% \text { a } \\
28 \% \text { da área total } \\
\text { da superfície } \\
\text { corporal }\end{array}$ & $\begin{array}{c}164 \\
\text { pacientes } \\
\text { pediátricos }\end{array}$ \\
\hline $\begin{array}{l}\text { Karlsson } \\
\text { et al. } \\
(2019)\end{array}$ & $\begin{array}{l}6 \text { meses } \\
\text { a } 6 \text { anos }\end{array}$ & 35 & 23 & $\begin{array}{l}\text { Lesão térmica } \\
\text { (escalduras) }\end{array}$ & $\begin{array}{l}\text { Queimaduras de II } \\
\text { grau de espessura } \\
\text { parcial }\end{array}$ & $\begin{array}{l}\text { Variou de } 10 \% \text { a } \\
20 \% \text { da área total } \\
\text { da superfície } \\
\text { Corporal }\end{array}$ & $\begin{array}{l}58 \text { pacientes } \\
\text { pediátricos }\end{array}$ \\
\hline $\begin{array}{l}\text { Lima et } \\
\text { al. } \\
(2020 a)\end{array}$ & $\begin{array}{l}18-50 \\
\text { anos }\end{array}$ & $\begin{array}{c}\text { Não } \\
\text { reportado }\end{array}$ & $\begin{array}{c}\text { Não } \\
\text { reportado }\end{array}$ & $\begin{array}{l}\text { Lesão térmica } \\
\text { (líquidos } \\
\text { quentes, fogo } \\
\text { e óleo quente) }\end{array}$ & $\begin{array}{l}\text { Queimaduras de II } \\
\text { grau superficial de } \\
\text { espessura parcial }\end{array}$ & $\begin{array}{l}\text { Variou de } 05 \% \text { a } \\
20 \% \text { da área total } \\
\text { da superfície } \\
\text { Corporal }\end{array}$ & 62 pacientes \\
\hline $\begin{array}{l}\text { Alam e } \\
\text { Jeffery } \\
(2019)\end{array}$ & $\begin{array}{l}19-80 \\
\text { anos }\end{array}$ & 6 & 4 & $\begin{array}{l}\text { Lesão térmica } \\
\text { (queimadura } \\
\text { de óleo de } \\
\text { cozinha) } \\
\end{array}$ & $\begin{array}{l}\text { Queimaduras de II } \\
\text { grau de espessura } \\
\text { parcial e profunda em } \\
\text { adultos }\end{array}$ & Não reportado & 10 pacientes \\
\hline $\begin{array}{l}\text { Lima et } \\
\text { al. } \\
(2020 \mathrm{c})\end{array}$ & $\begin{array}{l}2-12 \\
\text { anos }\end{array}$ & 18 & 12 & $\begin{array}{l}\text { Lesão Térmica } \\
\text { (escalduras e } \\
\text { fogo) }\end{array}$ & $\begin{array}{l}\text { Queimaduras de II } \\
\text { grau superficial, de } \\
\text { espessura parcial em } \\
\text { pacientes pediátricos. }\end{array}$ & $\begin{array}{l}\text { Variou de } 13 \% \text { a } \\
60 \%\end{array}$ & $\begin{array}{l}30 \text { pacientes } \\
\text { pediátricos }\end{array}$ \\
\hline
\end{tabular}

Fonte: Artigos analisados (2021). 
As informações referentes ao tipo de curativo biológico, indicação, tempo de intervenção e evolução dos casos podem ser consultadas no Quadro 5, a seguir. Observou-se que o curativo biológico mais utilizado foi o de pele de Tilápia do Nilo (De Miranda \& Brandt, 2019; Lima et al., 2020b; Alam \& Jeffery, 2019; Lima et al., 2020c) e o de tecido porcino (Burkey et al., 2016; Karlsson et al., 2019), indicados pelos estudos para queimaduras de segundo grau (De Miranda \& Brandt, 2019; Lima et al., 2020b; Diegidio et al., 2017; Burkey et al., 2016; Karlsson et al., 2019; Lima et al., 2020a; Alam \& Jeffery, 2019; Lima et al., 2020c). O tempo de intervenção variou entre 7 e 104 dias (De Miranda \& Brandt, 2019; Lima et al., 2020b; Diegidio et al., 2017; Burkey et al., 2016; Karlsson et al., 2019; Lima et al., 2020a; Alam \& Jeffery, 2019; Lima et al., 2020c), e os pacientes tratados com curativo biológico de pele de Tilápia do Nilo tiveram um menor tempo de intervenção quando comparados aos pacientes controle (De Miranda \& Brandt, 2019; Lima et al., 2020b; Alam \& Jeffery, 2019; Lima et al., 2020c), como se mostra no Quadro 5.

Os resultados mostraram que o tratamento de pacientes com curativo biológico evita a contaminação e perda de líquidos, causa menos dor, apresenta melhor cicatrização quando se trata de estética e tempo de internação, tem baixo custo e menor necessidade de trocas diárias, representando o curativo biológico de Pele de Tilápia do Nilo aquele com melhores resultados. 
Research, Society and Development, v. 10, n. 10, e175101018560, 2021

(CC BY 4.0) | ISSN 2525-3409 | DOI: http://dx.doi.org/10.33448/rsd-v10i10.18560

Quadro 5. Distribuição quanto ao tipo de curativo biológico, indicação, tempo de intervenção e evolução dos casos. Caxias, MA, Brasil, 2021.

\begin{tabular}{|c|c|c|c|c|c|}
\hline $\begin{array}{l}\text { Autor e } \\
\text { ano }\end{array}$ & $\begin{array}{l}\text { Tipo de } \\
\text { curativo } \\
\text { (grupo de } \\
\text { intervenção) }\end{array}$ & $\begin{array}{l}\text { Tipo de } \\
\text { curativo } \\
\text { (grupo } \\
\text { controle) }\end{array}$ & $\begin{array}{c}\text { Indicação } \\
\text { (grupo intervenção) }\end{array}$ & $\begin{array}{c}\text { Tempo de } \\
\text { intervenção }\end{array}$ & Evolução dos casos \\
\hline $\begin{array}{l}\text { De } \\
\text { Miranda } \\
\text { e Brandt } \\
(2019)\end{array}$ & $\begin{array}{l}\text { Curativo } \\
\text { biológico } \\
\text { oclusivo com } \\
\text { pele da } \\
\text { Tilápia-do- } \\
\text { Nilo. }(\mathrm{n}=15) \text {. }\end{array}$ & $\begin{array}{l}\text { Tratamento } \\
\text { com hidro } \\
\text { fibra com } \\
\text { prata } \\
\text { (Aquacel). (n } \\
=15)\end{array}$ & $\begin{array}{l}\text { Indicado como curativo } \\
\text { biológico oclusivo, no } \\
\text { manejo/tratamento de } \\
\text { queimaduras de } 2^{\circ} \text { grau } \\
\text { em adultos. }\end{array}$ & 7 e 12 dias & $\begin{array}{l}\text { Os resultados mostraram que os dias médios de tratamento de pacientes com pele de } \\
\text { tilápia do Nilo }(9,6 \pm 2,4) \text { e com AquacelAG® }(10,7 \pm 4,5) \text {. A pele da Tilápia se molda } \\
\text { e adere à ferida, criando uma espécie de tampão, que evita a contaminação e perda de } \\
\text { líquidos. } 86,7 \% \text { dos pacientes no grupo de pele de tilápia do Nilo sentiram alívio da } \\
\text { dor, vale ressaltar que nos casos tratados com a pele da Tilápia-do-Nilo, houve um } \\
\text { menor número de substituições de curativo em comparação com o Aquacel. }\end{array}$ \\
\hline $\begin{array}{l}\text { Lima et } \\
\text { al. } \\
(2020 b)\end{array}$ & $\begin{array}{l}\text { Pele da } \\
\text { Tilápia-do- } \\
\text { Nilo }\end{array}$ & Não se aplica & \begin{tabular}{l}
\multicolumn{3}{l}{ Indicado como curativo } \\
biológico no \\
manejo/tratamento de \\
queimaduras de \\
segundo grau profundo \\
em adultos.
\end{tabular} & 16 dias & $\begin{array}{l}\text { Período de } 16 \text { dias necessário para a reepitelização desta paciente. Houve efetividade } \\
\text { do xenoenxerto flexível e aderente, com ausência de antigenicidade e toxicidade. Foi } \\
\text { capaz de conservar a umidade, evitou a entrada de microrganismos, promovendo uma } \\
\text { diminuição do número de troca de curativos, redução das dores, diminuição dos custos } \\
\text { hospitalares, e de dias internação da paciente. }\end{array}$ \\
\hline $\begin{array}{l}\text { Diegidio } \\
\text { et al. } \\
(2017)\end{array}$ & $\begin{array}{l}\text { Xenoenxerto } \\
(\mathrm{n}=534)\end{array}$ & $\begin{array}{l}\text { Autoenxerto } \\
(\mathrm{n}=339)\end{array}$ & $\begin{array}{l}\text { Xenoenxerto é indicado } \\
\text { como terapia em lesões } \\
\text { por escaldadura } \\
\text { pediátrica de segundo } \\
\text { grau superficial. }\end{array}$ & $\begin{array}{l}\text { Grupo de } \\
\text { autoenxerto }(286 \\
\text { dias). Grupo de } \\
\text { xenoenxerto ( } 104 \\
\text { dias). }\end{array}$ & $\begin{array}{l}\text { O xenoenxerto oferece uma opção atraente para o fechamento de feridas em } \\
\text { queimaduras por escalda de espessura parcial, na população pediátrica. Menor tempo } \\
\text { de hospitalização e redução de despesas. Menor incidência de cicatriz hipertrófica e } \\
\text { menor necessidade de cirurgia reconstrutiva. Crianças com queimaduras profundas e } \\
\text { grandes áreas de superfície requerem autoenxerto. }\end{array}$ \\
\hline $\begin{array}{l}\text { Burkey et } \\
\text { al. (2016) }\end{array}$ & $\begin{array}{l}\text { Xenoenxerto } \\
\text { porcino }\end{array}$ & Não se aplica & $\begin{array}{lr}\text { Indicada } & \text { em } \\
\text { queimaduras } & \text { de } \\
\text { segundo } & \text { grau } \\
\text { superficiais } & \text { de } \\
\text { espessura parciais } & \text { em } \\
\text { pacientes pediátricos. }\end{array}$ & $\begin{array}{l}\text { Variação de } 14 \text { a } 31 \\
\text { dias }\end{array}$ & $\begin{array}{l}\text { Diminuição da necessidade de sedação moderada para trocas de curativos. Redução da } \\
\text { dor. Alta mais precoce do hospital. } \\
\text { A maioria das crianças consegue tolerar confortavelmente as trocas de curativos com } \\
\text { ou sem analgesia. }\end{array}$ \\
\hline
\end{tabular}


Research, Society and Development, v. 10, n. 10, e175101018560, 2021

(CC BY 4.0) | ISSN 2525-3409 | DOI: http://dx.doi.org/10.33448/rsd-v10i10.18560

\begin{tabular}{|c|c|c|c|c|c|}
\hline $\begin{array}{l}\text { Karlsson } \\
\text { et al. } \\
(2019)\end{array}$ & $\begin{array}{l}\text { Xenoenxerto } \\
\text { porcino } \\
(\mathrm{n}=30)\end{array}$ & $\begin{array}{l}\text { Espuma de } \\
\text { prata }(n=28)\end{array}$ & $\begin{array}{lr}\text { Indicada } & \text { em } \\
\text { queimaduras } & \text { de } \\
\text { segundo } & \text { grau } \\
\text { superficiais } & \text { de } \\
\text { espessura parciais } & \text { em } \\
\text { pacientes pediátricos. }\end{array}$ & $\begin{array}{l}\text { Espuma de prata } \\
9(7-23) \text { dias. } \\
\text { Xenoenxerto } \\
\text { porcino } 15(9-29) \\
\text { dias. }\end{array}$ & $\begin{array}{l}\text { Os pacientes tratados com curativo de espuma de prata tiveram um tempo de } \\
\text { cicatrização significativamente menor. O tempo médio para a cicatrização de } 97 \% \text { para } \\
\text { este grupo foi de } 9(7-23) \text { dias em comparação com } 15(9-29) \text { dias no grupo de } \\
\text { xenoenxerto porcino }(\mathrm{p}=0,004) \text {. O tempo médio para a cura completa para o grupo de } \\
\text { espuma de prata foi de } 15(9-29) \text { dias e para o grupo de xenoenxerto porcino de } 20,5 \\
(11-42) \text { dias }(\mathrm{p}=0,010) \text {. Dor, infecção da ferida, tempo de internação hospitalar e } \\
\text { proporção de operações foram semelhantes entre os grupos. O número de trocas de } \\
\text { curativos e o tempo para as trocas foram menores no grupo de espumas de prata ( } \mathrm{p}= \\
0,03 \text { para ambas as variáveis). }\end{array}$ \\
\hline $\begin{array}{l}\text { Lima et } \\
\text { al. } \\
(2020 a)\end{array}$ & $\begin{array}{l}\text { Curativo } \\
\text { biológico com } \\
\text { pele de } \\
\text { Tilápia-do- } \\
\text { Nilo. }\end{array}$ & $\begin{array}{l}\text { Sulfadiazina } \\
\text { de prata }\end{array}$ & $\begin{array}{l}\text { Indicada em } \\
\text { queimaduras de } \\
\text { segundo grau parcial e } \\
\text { profunda em adultos. }\end{array}$ & $\begin{array}{l}\text { Grupo Sulfadiazina } \\
\text { de prata (10-23 } \\
\text { dias). Grupo } \\
\text { Xenoenxerto } \\
\text { Tilápia (9-19 dias) }\end{array}$ & $\begin{array}{l}\text { Verificou-se que em participantes tratados com pele de tilápia a reepitelização } \\
\text { completa ocorreu em significativamente menos dias; a intensidade da dor relatada foi } \\
\text { menor; a quantidade de anestésicos / analgésicos necessários foi menor; e a } \\
\text { necessidade de trocas de curativos foi significativamente reduzida em comparação com } \\
\text { voluntários tratados com sulfadiazina de prata. }\end{array}$ \\
\hline $\begin{array}{l}\text { Alam e } \\
\text { Jeffery } \\
(2019)\end{array}$ & $\begin{array}{l}\text { Curativo } \\
\text { biológico com } \\
\text { a pele de } \\
\text { peixe. }\end{array}$ & Não se aplica & $\begin{array}{lrr}\text { Indicada } & \text { em } \\
\text { queimaduras } & \text { de } \\
\text { segundo } & \text { grau } & \text { e } \\
\text { espessura } & \text { parcial } & \text { em } \\
\text { adultos. } & & \end{array}$ & $\begin{array}{l}\text { Ambas as feridas } \\
\text { estavam } \\
\text { completamente } \\
\text { epitelizadas no } \\
\text { seguimento de } 2 \\
\text { semanas ( } 14 \text { dias) }\end{array}$ & $\begin{array}{l}\text { Não houve reações adversas observadas. A qualidade da cura do local doador foi } \\
\text { considerada boa em todos os casos. Tanto o efeito analgésico observado quanto os } \\
\text { tempos médios relativamente curtos até } 100 \% \text { de reepitelização são promissores. }\end{array}$ \\
\hline $\begin{array}{l}\text { Lima et } \\
\text { al. } \\
(2020 \mathrm{c})\end{array}$ & $\begin{array}{l}\text { Pele de } \\
\text { Tilápia-do- } \\
\text { Nilo }(n=15)\end{array}$ & $\begin{array}{l}\text { Sulfadiazina } \\
\text { de prata } \\
(\mathrm{n}=15)\end{array}$ & $\begin{array}{l}\text { Indicada em } \\
\text { queimaduras de II grau } \\
\text { superficial de espessura } \\
\text { parcial em pacientes } \\
\text { pediátricos. }\end{array}$ & $\begin{array}{l}\text { Sulfadiazina prata: } \\
\text { reepitelização entre } \\
\text { 10-11 dias. Pele de } \\
\text { Tilápia-do-Nilo: 9- } \\
10 \text { dias. }\end{array}$ & $\begin{array}{l}\text { A pele de tilápia mostrou boa aderência ao leito da ferida, reduzindo número de trocas } \\
\text { de curativos necessárias e, consequentemente, a quantidade de anestésicos utilizados, } \\
\text { auxiliando no processo de cicatrização, reduzindo a perda de fluidos. Reduz o número } \\
\text { de dias para completar a cicatrização de feridas de queimadura e recurso efetivo de } \\
\text { baixo custo. E a diminuição das dores foi semelhante ao tratamento convencional com } \\
\text { sulfadiazina de prata. }\end{array}$ \\
\hline
\end{tabular}

Fonte: Artigos analisados (2021). 


\section{Discussão}

\section{Caracterização sociodemográfica e clínica dos pacientes queimados tratados com curativos heterólogos}

Os resultados evidenciam que a idade dos pacientes participantes dos estudos analisados variou entre 6 meses e 80 anos, com dados expressivos em pacientes pediátricos e adultos, assim como os resultados apresentados no estudo de Karlsson et al. (2019), realizado com tecido porcino. Já a pesquisa realizada na China por Guo et al. (2015) com 60 pacientes apontou resultados divergentes, evidenciando que houve prevalência de paciente idosos.

Quanto ao sexo, dois estudos (Diegidio et al. 2017; Burkey et al., 2016) mostram que houve um predomínio de indivíduos do sexo feminino, prevalência que se fez presente também nos estudos de Torrisi, Silva, Carvalho e Miranda (2018), que relaciona esse fato às atividades profissionais e domésticas, como cozimento em fogo aberto ou em fogões, situações que oferecem riscos. A Organização Mundial da Saúde (2018) declara que chamas abertas usadas para aquecimento e iluminação representam riscos, bem como a violência autodirigida ou interpessoal. Em contrapartida, Guo et al. (2015) e Karlsson et al. (2020) apresentaram em seu estudo a prevalência do sexo masculino.

Os estudos de Lima et al. (2020b), Diegidio et al. (2017), Burkey et al. (2016), Karlsson et al. (2019) e Lima et al. (2020c) evidenciaram que, em relação ao tipo de queimadura, todos os pacientes apresentaram lesão térmica, e as queimaduras mais comuns são por escalduras em ambiente doméstico. Em relação ao grau de acometimento por queimaduras de II grau profundo e superficial Lima et al. (2020c) em seu estudo obtiveram achados de pacientes que apresentaram lesão térmica causada por uma explosão de pólvora. O uso de curativo heterólogo pode, de acordo com a afirmativa de Gimenez et al. (2019), ser utilizado em queimaduras de terceiro grau.

Os agentes potencialmente causadores de injúrias térmicas são os líquidos superaquecidos, que, em sua maioria, ocorrem em cozinhas (Nazário, Leonardi, \& Nitschke, 2014). Corroborando com isso, o estudo de Burkey et al (2016) revela um número considerável de casos de queimaduras causadas por escaldadura, chama e óleo.

No que concerne ao percentual de acometimento total da superfície corporal, foi constatado uma variância entre $0,5 \%$ a 60\%, com prevalência entre 10\% a 20\%, respectivamente (De Miranda \& Brandt, 2019; Lima et al., 2020b; Diegidio et al., 2017; Burkey et al., 2016; Karlsson et al., 2019; Lima et al., 2020a; Lima et al., 2020c). Desse modo, Costa et al. (2019) e Guo et al. (2015), obtiveram achados semelhantes quando detalham o acometimento de $18 \%$ e $50 \%$ da superfície corporal total.

\section{Tratamento de queimaduras com xenoenxerto de diferentes espécies}

O uso de curativos biooclusivos pode prevenir perdas hidroeletrolíticas, prevenir a contaminação bacteriana, promover a formação epitelial e facilitar a formação de tecido de granulação para enxertia. Tecidos biológicos de origem animal, pele de porco, rã, peixe, pericárdio bovino e submucosa suína são alguns dos materiais utilizados para esses curativos (Miranda, 2018).

Entre as espécies utilizadas para o tratamento de queimaduras com curativo heterólogo, a pele de Tilápia do Nilo, nos estudos de De Miranda e Brandt (2019), Lima et al. (2020b), Alam e Jeffery (2019) e Lima et al. (2020c), e o tecido porcino, nos estudos Burkey et al. (2016) e Karlsson et al. (2019), foram identificados como os curativos biológicos mais utilizados. Durante a busca nas bases de dados, não foram encontrados artigos de estudos in vivo com humanos que retratassem o uso de curativo biológico de outras espécies além das supracitadas, o que representa uma limitação deste estudo.

\section{Indicação clínica do tratamento de queimaduras por xenoenxerto}

Os resultados mostraram a utilização eficaz dos curativos biológicos de pele de tilápia e de tecido porcino no tratamento de lesão térmica de segundo grau. Outro resultado essencial acerca do curativo heterólogo foi o de Gimenez et al. (2019), que evidencia o uso desse tratamento em queimaduras também de terceiro grau. 
Foi evidenciado ainda, que o uso de xenoenxerto porcino é indicado em injúrias térmicas de segundo grau de espessura parciais em pacientes pediátricos (Burkey et al., 2016), similaridade de dados nos achados de Karlsson et al. (2020).

O estudo de Diegidio et al. (2017) evidenciou que a xenoenxertia deve ser fortemente considerada como terapia de primeira linha para lesões por escaldadura pediátrica de profundidade intermediária. Corroborando com essa afirmativa, o estudo de Lima et al. (2020c) destaca que, em pacientes pediátricos, a supervisão inadequada de um adulto, abuso infantil, pobreza, aglomeração de crianças em um local com riscos de queimaduras, educação inadequada e não ser filho ou filha biológica do agregado familiar são fatores de risco para a ocorrência de queimaduras em crianças.

\section{A eficácia de transplante heterólogo no tratamento de queimaduras}

De acordo com o estudo feito por Miranda (2018), a pele da tilápia tem características morfológicas semelhantes às da pele humana. Tem feixes de colágeno comprimido, longo e organizado, principalmente do tipo I, garante flexibilidade satisfatória, o que permite um bom manejo em manobras de cirurgia.

Com base nos achados, evidenciou-se que o tempo de intervenção variou entre 7 a 104 dias (De Miranda \& Brandt, 2019; Lima et al., 2020b; Diegidio et al., 2017; Burkey et al., 2016; Karlsson et al., 2019; Lima et al., 2020a; Alam \& Jeffery, 2019; Lima et al., 2020c), dessa forma, foi observada a prevalência de reepitelização entre 12 a 16 dias do tratamento. Os pacientes tratados com curativo biológico de pele de Tilápia do Nilo tiveram um menor tempo de intervenção e teve melhores resultados (De Miranda \& Brandt, 2019; Lima et al., 2020b; Alam \& Jeffery, 2019; Lima et al., 2020c). Os resultados mostraram ainda que o tratamento de pacientes com curativo biológico evita a contaminação e perda de líquidos, promove uma diminuição da dor, apresenta melhor cicatrização quando se trata de estética e tempo de internação, tem baixo custo e menor necessidade de trocas diárias.

Um estudo de caso (Lima et al., 2020b), realizado com uma paciente adulto do sexo feminino, evidenciou que o tratamento com pele de Tilápia no período de 16 dias foi suficiente para reepitelização da queimadura, demonstrando que houve efetividade da pele de tilápia como um xenoenxerto flexível e aderente, com ausência de antigenicidade e toxicidade, e capacidade de conservar a umidade e evitar infecções. Torrisi et al. (2018) obtiveram resultados semelhantes. Quando utilizaram o tratamento com pele de Tilápia em um paciente, observaram que houve diminuição da dor, menor tempo de cura, redução de custos no tratamento e diminuição de possibilidade de complicações, como por exemplos, as infecções. Outro estudo que obteve resultados semelhantes foi o de Miranda (2018).

Corroborando com a afirmativa acima, o estudo de Costa et al. (2020), dessa vez realizado com um paciente pediátrico de 3 anos, mostrou que o tratamento com pele de Tilápia trouxe boa aderência ao leito da ferida. O paciente recebeu alta hospitalar com um total de 10 dias, necessários para a completa reepitelização da queimadura de espessura parcial superficial e nenhum efeito adverso foi notado. Em contrapartida, Guo et al. (2015) evidenciaram que, no estudo com 60 pacientes adultos com queimadura dérmicas e profundas, superior a $50 \%$ da superfície corporal, o tecido porcino facilita a cicatrização das feridas, reduz a internação hospitalar, melhora os resultados estéticos e funcionais, e os pacientes receberam alta em uma média de 28 dias.

O estudo de De Miranda e Brandt (2019), realizado em pacientes adultos em Recife, ratificou que o tratamento de queimaduras com pele de Tilápia-do-Nilo é eficaz como curativo biológico oclusivo, comparado ao tratamento convencional, observando que, a média de dias de tratamento foi similar aos tratados com curativo com o Aquacel AG® para a completa cicatrização ou reepitelização da ferida. Também não houve inferioridade da referência de dor do paciente após a aplicação do curativo, entre os pacientes tratados com a pele da Tilápia-do-Nilo e os tratados com o Aquacel AG®.

O estudo transversal de Burkey et al. (2016) com 164 pacientes pediátricos nos Estados Unidos apresentou que o tratamento com xenoenxerto porcino atingiu resultados semelhantes aos apresentados pela pele de tilápia, com diminuição da 
necessidade de sedação moderada para trocas de curativos, redução das dores, alta hospitalar precoce, e a possibilidade de tolerância confortável às trocas de curativos com ou sem analgesia pelas crianças.

Devido às características biológicas da matriz dérmica acelular do porco, sua capacidade de suportar a regeneração de tecidos, repor fibroblastos, revascularizar, depositar novo colágeno e, eventualmente, absorver e ser substituído por tecido natural, esse tipo de pele tem sido amplamente utilizado para tratar queimaduras cutâneas profundas. A matriz dérmica acelular porcina estimula a síntese de colágeno, proliferação e diferenciação de células-tronco, expressão de fatores de crescimento relacionados e melhora a cicatrização de feridas (Guo et al., 2015).

Já a pesquisa realizada por Karlsson et al. (2020) revelou que os pacientes pediátriscos com escaldaduras de espessura parcial tratados com curativo de espuma de prata, em comparação aos curativos de xenoenxerto porcino, tiveram um tempo de cicatrização significativamente menor, e o número de trocas de curativos e o tempo para as trocas foram menores. No grupo de espumas de prata, não foram encontradas diferenças nos níveis de dor, na duração da internação hospitalar ou nas taxas de infecção entre os curativos. Os resultados do estudo de Diegidio et al. (2017) salientaram que a xenoenxertia permite alta hospitalar mais precoce, reduz a necessidade de reconstrução, para lesões por escaldadura pediátrica de profundidade intermediária.

\section{Considerações Finais}

O estudo permitiu uma avaliação do tratamento de queimaduras por meio da terapia com curativo heterólogo, concluindo que ele é eficaz. Desse modo, foi possível responder os objetivos propostos. Quanto ao tipo de espécies encontrados, evidenciou o tratamento com pele de tilápia do Nilo e curativo porcino, e, na busca eletrônica empregada, não foi encontrado tratamento com outras espécies além das supracitadas.

Nessa perspectiva, foi possível perceber que o curativo com pele de tilápia do Nilo teve resultados estatisticamente mais significativos, quando comparado a todas as outras intervenções, incluindo com curativo biológico porcino. Foi possível perceber ainda que a pele da tilápia teve melhor eficácia quando comparada ao tecido porcino e tratamento convencional em relação ao tempo de tratamento, reepitelização, trocas de curativos, menor tempo de internação. Quanto à indicação clínica, a maior parte das intervenções foram realizadas em pacientes pediátricos e adultos, com lesões por escaldadura de segundo grau superficial e profunda.

A atuação da enfermagem é fundamental para garantir qualidade e segurança aos pacientes queimados. Por meio dessa pesquisa, foi possível perceber a importância da equipe de Enfermagem em proporcionar assistência abrangente e eficaz, pois oferece segurança e conforto aos pacientes com grandes queimaduras, a fim de minimizar sua dor. Visto que a qualidade do atendimento é de extrema importância, a meta é reduzir a dor e prevenir infecção e sequelas físicas e mentais. Nesse sentido, vê-se a importância do conhecimento do profissional da Enfermagem acerca dos procedimentos do curativo heterólogo e seus benefícios para a saúde mental e física dos pacientes.

Por fim, a pesquisa possibilitou a expansão de conhecimentos acerca do tratamento de queimaduras por meio de curativo heterólogo. Espera-se, assim, que os resultados favoreçam o conhecimento sobre o tema e permitam a melhoria da prática em saúde, considerando-se que outros estudos sejam realizados. Vale destacar ainda a importância da execução de outros estudos, como ensaios clínicos randomizados, especialmente com curativo biológico porcino e outros tipos de animais, para que seja possível comprovar o tratamento de queimaduras com tecidos de diferentes espécies, além das identificadas, permitindo desse modo, a generalização dos resultados. 


\section{Referências}

Alam, K., \& Jeffery S. L. A. (2019). Acellular Fish Skin Grafts for Management of Split Thickness Donor Sites and Partial Thickness Burns: A Case Series. Mil Med, 184, 16-20.

Alves, A. P. N. N., Verde, M. E. Q. L., Ferreira, A. E. C., Jr.; Silva, P. G. B., Feitosa, V. P., Lima, E. M., Jr., Moraes, M. O., Fº (2015). Avaliação microscópica, estudo histoquímico e análise de propriedades tensiométricas da pele de tilápia do Nilo. Rev Bras Queimaduras, 14(3), $203-210$.

Belém, T. C. (2016). Perfil de uso de antibióticos em pacientes da unidade de queimados do hospital regional da asa norte (Trabalho de Conclusão de Curso). Universidade Nacional de Brasília, Ceilândia, DF, Brasil. https://bdm.unb.br/bitstream/10483/17572/6/2016_ThaisClaroBelem_tcc.pdf.

Bork, A. M. T. (2011). Enfermagem baseada em evidências. Guanabara Koogan.

Burkey, B., Davis, W., Glat, P. M. (2016). Porcine xenograft treatment of superficial partial-thickness burns in paediatric patients. Journal Of Wound Care, 25(2), 10-15.

Carlucci, V. D. S., Rossi, L. A., Ficher, A. M. F. T., Ferreira, E., \& Carvalho, E. C. (2007). A experiência da queimadura na perspectiva do paciente. Revista da Escola de Enfermagem da Usp, 41(1), 21-28.

Costa, B. A., Lima, E. M., Jr, Moraes, M. O, F', Fechine, F. V, Moraes, M. E. A., Silva, F. R., Jr., \& Rocha, M. B. S. (2019). Use of Tilapia Skin as a Xenograft for Pediatric Burn Treatment: a case report. Journal Of Burn Care \& Research, 40(5), 714-717.

Dalla-Corte, L. M., Fleury, B. A. G., Huang, M., Adorno, J., \& Modelli, M. E. S. (2019). Perfil epidemiológico de vítimas de queimaduras internadas em uma unidade no Distrito Federal do Brasil. Rev Bras Queimaduras, 18(1), 10-15.

De Miranda, M. J. B., \& Brandt, C. T. (2019). Nile tilapia skin xenograft versus silver-based hydrofiber dressing in the treatment of second-degree burns in adults. Revista Brasileira de Cirurgia Plástica (Rbcp), 34(1), 79-95.

Diegidio, P., Hermiz, S. J., Ortiz-Pujols, S., Jones, S. W., Duin, D. V., Weber, D. J., \& Hultman, C. S. (2017). Even Better Than the Real Thing? Xenografting in Pediatric Patients with Scald Injury. Clin Plast Surg, 44(3), 651-656.

Ercole, F. F., Melo, L. S., \& Alcoforado, C. L. G. C. (2014). Revisão integrativa versus revisão sistemática. Reme, 18(1), 9-11.

Gimenez, C. E. A., Bianco, A. G. C., Monteiro, E. S., Ribas, A. M., Beutler, E. C., Mazzo, M. B., \& Costa, E. N. (2019). A pele da tilápia no tratamento de queimaduras de segundo e terceiro graus, além de mais eficiente, é de baixíssimo custo. Revista Enfermagem Atual In Derme, 87(25), 1-2.

Guo, Z. Q., Qiu, L., Gao, Y., Li, J. H., Zhang, X. H., Yang, X. L., \& Chen, X. L. (2015). Use of porcine acellular dermal matrix following early dermabrasion reduces length of stay in extensive deep dermal burns. Burns, 42(3), 598-604.

Karlsson, M., Elmasry, M., Steinvall, I., Sjöberg, F., Olofsson, P., \& Thorfinn, J. (2019). Superiority of silver-foam over porcine xenograft dressings for treatment of scalds in children: A prospective randomised controlled trial. Burns, 45(6), 1401-1409.

Lima, E. M., Jr., Moraes, M. O., F', Costa, B. A., Rohleder, A. V. P., Rocha, M. B. S., Fechine, F. V., \& Moraes, M. E. A. (2020). Innovative Burn Treatment Using Tilapia Skin as a Xenograft: a phase ii randomized controlled trial. Journal Of Burn Care \& Research, 41(3), 585-592.

Lima, E. M., Jr., Moraes, M. O., F', Forte, A. J., Costa, B. A., Fechine, F. V., Alves, A. P. N. N., \& Mathor, M. B. (2020). Pediatric Burn Treatment Using Tilapia Skin as a Xenograft for Superficial Partial-Thickness Wounds: A Pilot Study. J Burn Care Res, 41(2), 241-247.

Lima, E. M., Moraes, M. O., Costa, B. A., Uchôa, A. M. N., Martins, C. B., Moraes, M. E. A., \& Fechine, F. V. (2020). Tratamento de queimaduras de segundo grau profundo em abdômen, coxas e genitália: uso da pele de tilápia como um xenoenxerto. Rev. Bras. Cir. Plást, 35(2), $243-248$.

Miranda, M. J. B. (2018). Estudo comparativo entre xenoenxerto (pele da tilápia-do-nilo) e hidrofibra com prata no tratamento das queimaduras de II grau em adultos (Dissertação de mestrado). Universidade Federal de Pernambuco, Recife, PE, Brasil. https://repositorio.ufpe.br/bitstream/123456789/ 33439/1/DISSERTA\%c3\%87\%c3\%830\%20Marcelo\%20Jos\%c3\%a9\%20Borges\%20de\%20Miranda.pdf.

Nazário, N. O., Leonardi, D. F., \& Nitschke, C. A. S. (2014). Queimaduras. Universidade Federal de Santa Catarina.

Oliveira, F. B. M., Costa, A. C. A. L., Alves, D. L., França, J. F., Macedo, M. S., \& Santos, R. D. (2016). Relação entre a sobrecarga de trabalho e erros de administração de medicação na assistência hospitalar. Revista Ciências \& Saberes, 2(2), 325-334.

Organização Mundial de Saúde. (2018). Burns Fact Sheet $n^{\circ}$ 365. OMS. Recuperado de https://www.who.int/en/news-room/fact-sheets/detail/burns.

Pinho, F. M., Sell, B. T., Sell, C. T., Senna, C. V. A., Martins, T., Foneca, E. S., \& Amante, L. N. (2017). Cuidado de enfermagem ao paciente queimado adulto: uma revisão integrativa. Rev Bras Queimaduras, 16(3), 181-187.

Torrisi, A. C., Silva, P. G. P., Carvalho, S. M. F. F., \& Miranda, M. J. B. (2018). Pele da tilápia do Nilo (Oreochromis niloticus) como curativo biológico no tratamento de queimaduras: relato de caso. An Fac Med Olinda, 2(2), 65. 